\title{
Deformation prediction and Finite Element Analyses of precision seamless tubes during cold drawing
}

\author{
Martin Necpal ${ }^{1, *}$, Maroš Martinkovič ${ }^{1}$ and Ivan Buranský ${ }^{1}$ \\ ${ }^{1}$ Slovak University of Technology, Faculty of Materials Science and Technology in Trnava, Institute \\ of Production Technologies, J. Bottu 25, 917 24, Trnava, Slovakia
}

\begin{abstract}
This paper deals with the deformation of precision seamless tubes during the cold drawing process, using Finite Element Methods. The value of strain obtain by stereology measurement of degree grain boundaries deformation are compared with simulation result for each drawing pass. The material chosen was the E235 and E355 steel grade, which is drawn from the initial dimension of $\Phi 70 \times 6.3 \mathrm{~mm}$ to the final dimension of $\Phi 50 \times 3.75 \mathrm{~mm}$ by two passes. FEM Software DEFORM 2D with the Lagrangian method is used to numerical analyses of the cold drawing process.
\end{abstract}

\section{Introduction}

Cold drawing technology used for manufacturing of precision seamless tube depends on many factors. Cold forming process parameters, tool geometry initial and final tube dimension are selected to ensure a high quality of the tubes. In order to achieve the final diameter and wall thickness, tubes are reduced successively in several cold drawing steps. This can be done by either drawing the tube through a die and by adding a plug, which results in better defined wall thickness and inner surface quality. Cold drawing using a fixed plug is a versatile technology that is used usually in the Železiarne Podbrezová ironworks company. The experiment results of this company are compared with the numerical simulation described in this paper.

\section{Experimental Material}

In this work, steel grade E235 and E355 (ferritic-pearlitic carbon steel, see Table 1 [1]) was considered; as a feedstock for cold drawing, hot rolled tube with dimensions of $\varnothing 70 \times 6.3 \mathrm{~mm}$ was selected. Mechanical properties of E235 steel are as follows: yield stress $\mathrm{R}_{\mathrm{e}}=(226 \div 245) \mathrm{MPa}$, tensile strength $\mathrm{R}_{\mathrm{m}}=(343 \div 441) \mathrm{MPa}$, ductility $\mathrm{A}_{5}=24 \%$, mechanical properties of E355 steel are as follows: yield stress $R_{e}=(335 \div 355) \mathrm{MPa}$, tensile strength $\mathrm{R}_{\mathrm{m}}=(490 \div 630) \mathrm{MPa}$, ductility $\mathrm{A}_{5}=24 \%$ [2].

\footnotetext{
*Corresponding author: martin.necpal@stuba.sk
} 
Table 1. Chemical composition of E235 and E355 steel grade in wt \%.

\begin{tabular}{|l|c|c|c|c|c|c|c|c|c|c|c|}
\hline & $\mathrm{C}$ & $\mathrm{Mn}$ & $\mathrm{Ni}$ & $\mathrm{Cu}$ & $\mathrm{Mo}$ & $\mathrm{Sn}$ & $\mathbf{P}$ & $\mathrm{S}$ & $\mathrm{Si}$ & $\mathrm{Ti}$ & $\mathrm{Cr}$ \\
\hline E235 & 0.090 & 0.420 & 0.060 & 0.140 & 0.020 & 0.012 & 0.013 & 0.011 & 0.200 & 0.002 & 0.060 \\
\hline E355 & 0.180 & 1.220 & 0.110 & 0.170 & 0.030 & 0.017 & 0.025 & 0.012 & 0.270 & 0.002 & 0.100 \\
\hline
\end{tabular}

\subsection{Workpiece and tools of material modelling}

As the temperature stays lower in cold drawing, the material properties do not vary and can therefore be supposed to by independent of the temperature variation. As the material behavior is considered temperature independent, the power law constitutive equation of material plastic properties can be used eq. 1. Where $\varepsilon$ represent the equivalent effective plastic strain, $\dot{\varepsilon}$ represent the effective plastic strain rates, and $c, n, m, y$ material parameters are determined by means of tensile tests $[1,5]$, they are listed in Table 2 . The tube material was considered as plastic, the hardening is assumed as isotropic, and yield function type is set as Von Mises.

The geometry of the tube has been meshed. The eight elements are across the wall of the tube in first pass the six are in second pass Fig. 5. This mesh of workpiece is sufficient for accuracy and does not need to be re-mesh procedure during the calculation.

The forming tools, (mandrel and die) was considered as rigid bodies. The mesh of tools did not need to be generated for simulation.

$$
\sigma=c \varepsilon^{n} \dot{\varepsilon}^{m}+y
$$

Table 2. Mechanical properties of the stainless steel materials.

\begin{tabular}{|c|c|c|c|}
\hline \multicolumn{2}{|c|}{} & E235 material & E355 material \\
\hline$c$ & Material constant (-) & 178 & 404 \\
\hline$n$ & Strain exponent (-) & 0.61 & 0.63 \\
\hline$m$ & Strain rate exponent (-) & 0.02 & 0.02 \\
\hline$y$ & Initial yield value (MPa) & 235.5 & 345 \\
\hline
\end{tabular}

\subsection{Numerical simulation}

DEFORM 2D and the Lagrangian calculation has been set for numerical simulation of cold drawing technology, according to the tool dimension given on Table 3. The initial axisymmetric geometric configuration has been set. The drawing velocity was $9 \mathrm{~m} . \mathrm{min}^{-1}$ for all passes in experimental drawing and simulation boundary conditions. The friction model between the tools and the material was chosen to be a shear-type with the value of 0.08 . The data interpolation functionality was used to set the second pass calculation. The final data from first pass was transfer, and to set second pass. This data transformation must be done, because drawing technology were performed without an interoperative annealing.

\subsection{Tube Drawing Technology}

The main production steps for tube cold drawing technology in Železiarne Podbrezová are as follows:

- feedstock pre-processing (hot rolled tube with dimensions of $\varnothing 70$ x $6.3 \mathrm{~mm}$ ).

- cold/hot pointing of tube ends (target diameter $40 \mathrm{~mm}$ ). 
- chemical treatment of the tube (pickling, phosphating, lubrication).

- cold drawing (see Tab. 3 for details).

- intermediate annealing and final annealing in protective atmosphere.

- final conditioning.

- surface inspection, packaging, rust-proofing.

- dispatch.

The final reduction of the tube area for two-pass technology (from $\varnothing 70 \times 6.3 \mathrm{~mm}$ to $\varnothing 50 \times 3.75 \mathrm{~mm}$ ) was $57.78 \%$; the value was divided rather uniformly among all passes (see Table 3). Calculation of tube cross-section (area) reduction:

$$
\text { Reduction }=\frac{S_{\mathrm{R}}}{S_{0}} \cdot 100[\%],
$$

Where:

$\mathrm{S}_{\mathrm{R}}=\mathrm{S}_{0}-\mathrm{S}\left[\mathrm{mm}^{2}\right]$ and

$\mathrm{S}_{0}$ - tube area before drawing $\left[\mathrm{mm}^{2}\right]$,

$\mathrm{S}-$ tube area after drawing $\left[\mathrm{mm}^{2}\right]$.

In the 1 st pass the area reduction was $40.52 \%$, and in the 2 nd pass the area reduction was $27.34 \%$.

Table 3. Parameters of tube drawing (O.D. - Outer Diameter, W.T. - Wall Thickness, L - Length).

\begin{tabular}{|c|c|c|c|c|c|c|c|c|c|c|c|}
\hline & \multicolumn{3}{|c|}{$\begin{array}{c}\text { Feedstock } \\
\text { dimensions [mm] }\end{array}$} & \multicolumn{3}{c|}{$\begin{array}{c}\text { Tube dimensions } \\
{[\mathbf{m m}]}\end{array}$} & \multicolumn{2}{c|}{$\begin{array}{c}\text { Pointing } \\
{[\mathrm{mm}]}\end{array}$} & \multicolumn{3}{c|}{$\begin{array}{c}\text { Reduction } \\
{[\%]}\end{array}$} \\
\hline $\begin{array}{c}\text { Pass } \\
\text { No. }\end{array}$ & O.D. & W.T. & L & O.D. & W.T. & L & L (tip) & Ø (tip) & Total & W.T. & O.D. \\
\hline 1 & 70 & 6.30 & 4300 & 55 & 4.75 & 6725 & 300 & 40 & 40.52 & 25 & 21 \\
\hline 2 & 55 & 4.75 & 6725 & 50 & 3.75 & 9255 & 300 & 40 & 27.34 & 21 & 9 \\
\hline
\end{tabular}

Local plastic deformation of tube was analyzed. During subsequent drawing steps, the tube undergoes plastic deformation. Final geometry and properties of deformed tubes depends on strain value. It is possible to investigate change of material structure and predict plastic deformation.

The microstructure of each pas was observed in orthogonal tangential and longitudinal plane of deformed tube with about 500x magnification of light microscope and metallographic cut Fig1. Tangential metallographic cut is don three times. On the inside of the pipe surface "I", on the outside of the pipe surface "O" and on the middle "M" of the pipe wall Fig. 2. Due to plastic deformation, the structure anisotropy increased - grain boundaries orientation in deformed place of piece was observed. The local strain in analyzed place was obtained by stereological measurement of degree of grain boundaries orientation $[4,6]$. The anisotropic microstructure was decomposed into isotropic and planar oriented components using quantitative metallography [3, 4] (Saltykov stereology methods with oriented test lines). Measured and calculated parameters of local plastic deformation in deformed zone are listed in Table 4. 

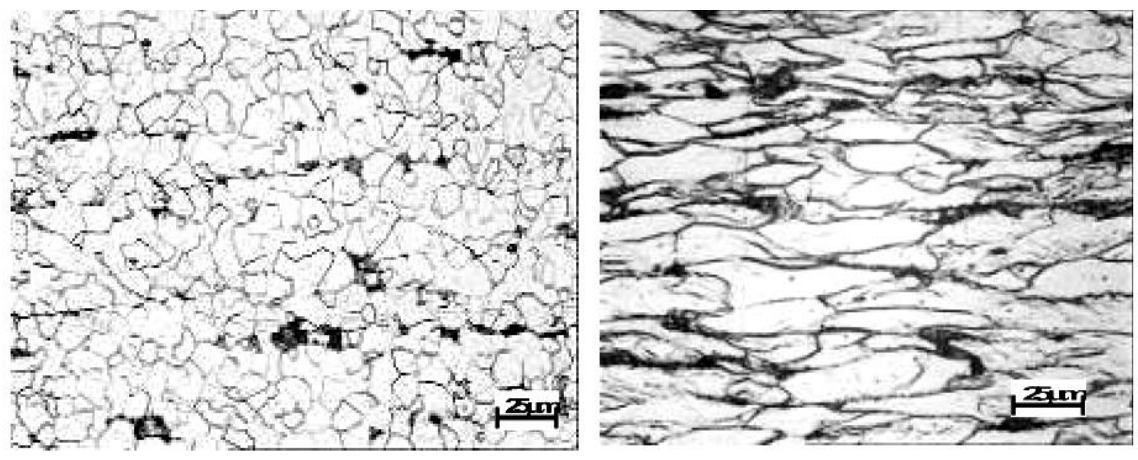

Fig. 1. Example of undeformed microstructure (left), deformation after 2 pass (right) [1].

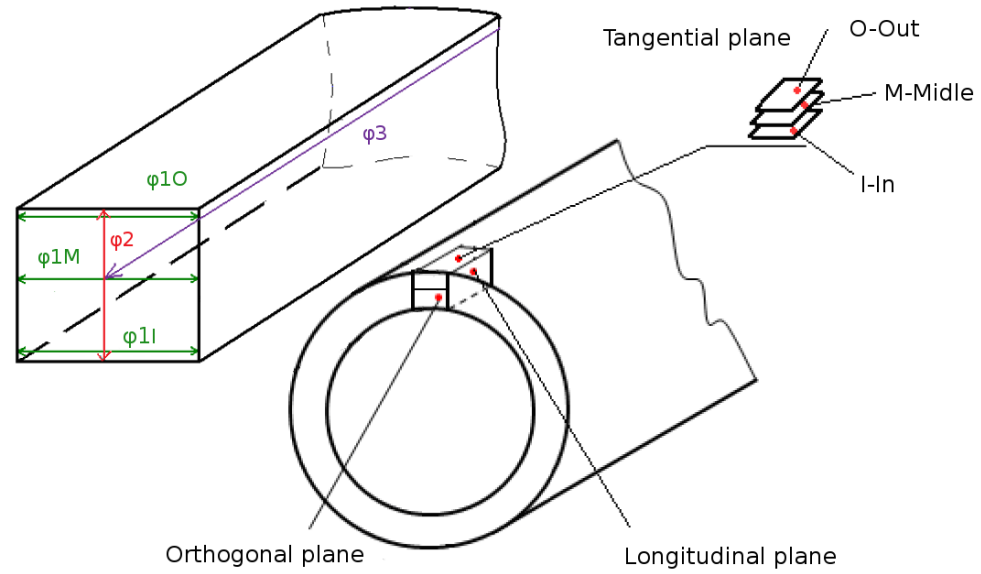

Fig. 2. Metallographic cuts and planes on the part of the deformed tube.

Table 4. Stereology methods and simulation strain values result.

\begin{tabular}{|c|c|c|c|c|c|c|c|c|c|c|c|}
\hline & \multicolumn{5}{|c|}{$\begin{array}{c}\text { Values obtained by stereological } \\
\text { measurement }[1]\end{array}$} & \multicolumn{5}{|c|}{ Values obtained by simulation } \\
\hline & & $\varphi 10$ & $\varphi 1 \mathrm{M}$ & $\varphi 1 \mathrm{I}$ & $\varphi 2$ & $\varphi 3$ & $\varphi 10$ & $\varphi 1 \mathrm{M}$ & $\varphi 1 \mathrm{I}$ & $\varphi 2$ & $\varphi 3$ \\
\hline \multirow{2}{*}{$\stackrel{\sim}{\tilde{1}}$} & Pass 1 & $-0,241$ & $-0,237$ & $-0,215$ & $-0,282$ & 0,520 & $-0,243$ & $-0,239$ & $-0,232$ & $-0,298$ & 0.537 \\
\hline & Pass 2 & $-0,336$ & $-0,320$ & $-0,301$ & $-0,519$ & 0,839 & $-0,339$ & $-0,324$ & $-0,305$ & $-0,551$ & 0,874 \\
\hline & Pass 1 & $-0,241$ & $-0,237$ & $-0,232$ & $-0,282$ & 0,520 & $-0,243$ & $-0,239$ & $-0,233$ & $-0,297$ & 0,536 \\
\hline & Pass 2 & $-0,336$ & $-0,320$ & $-0,300$ & $-0,519$ & 0,839 & $-0,339$ & -0.324 & $-0,305$ & $-0,55$ & 0,874 \\
\hline
\end{tabular}

\section{Results and discussion}

After simulation, it was possible to compare the strain values obtained by stereological method and the values obtain by the simulation. The strain in all directions according Fig. 2, was analyzed. Theta $\varphi 1$ strains are analyzed in three sections by the cross-section of the tube wall Fig. 2, 3. Strain $\varphi 1 \mathrm{I}$ is near the inner surface, strain $\varphi 1 \mathrm{O}$ is near the out surface, and 
strain $\varphi 1 \mathrm{M}$ is in the middle of the tube wall. As shown in Fig. 3, after the 1 pass, the difference of strain between the E235 and E355 is minimal. On the inside, "A" of the tube is smaller negative strain, that on the outside " $\mathrm{B}$ " of the tube. The same result is after pass 1 .

Calculated values of Radial $\varphi 2$ strain for all passes and materials can be seen in Fig. 4. Due to high reduction $40.52 \%$ after the first pass, there is observable positive $\varphi 2$ strain in deformed area. After the second pass, where the reduction area is $27.34 \%$, there is only negative $\varphi 2$ strain.

Calculated values of $\varphi 3$ strain for all passes and materials can be seen in Fig. 5.
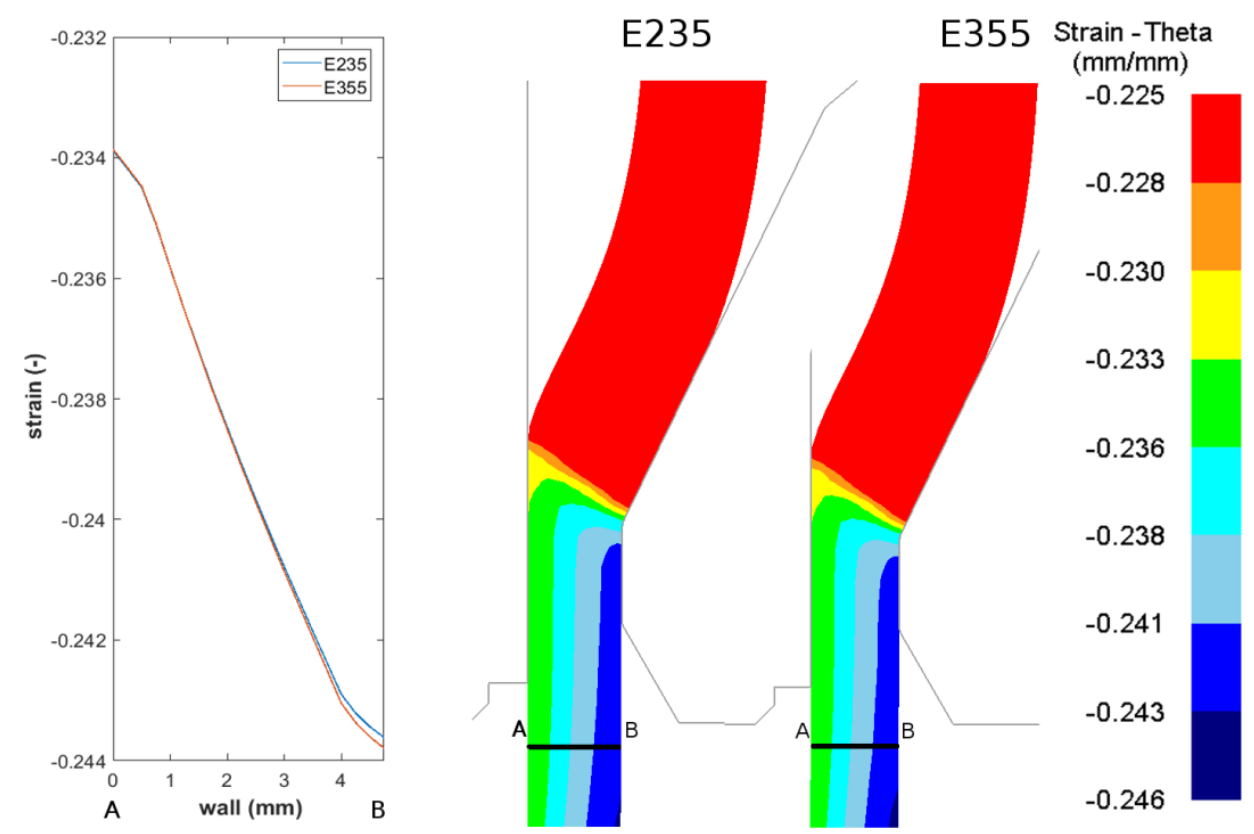

Fig. 3. Strain $\varphi 1$ across the wall of the tube after 1 pass.

Initial strain of tube which is not deformed is 0 . After first pass $\varphi 3$ strain is approximately 0.54 for E235 and also E355 material Fig. 5 left. The data interpolation method was used for initialization of second pass. Initial strain for second pass is between 0.550 and 0.625 (Fig. 5, right). 


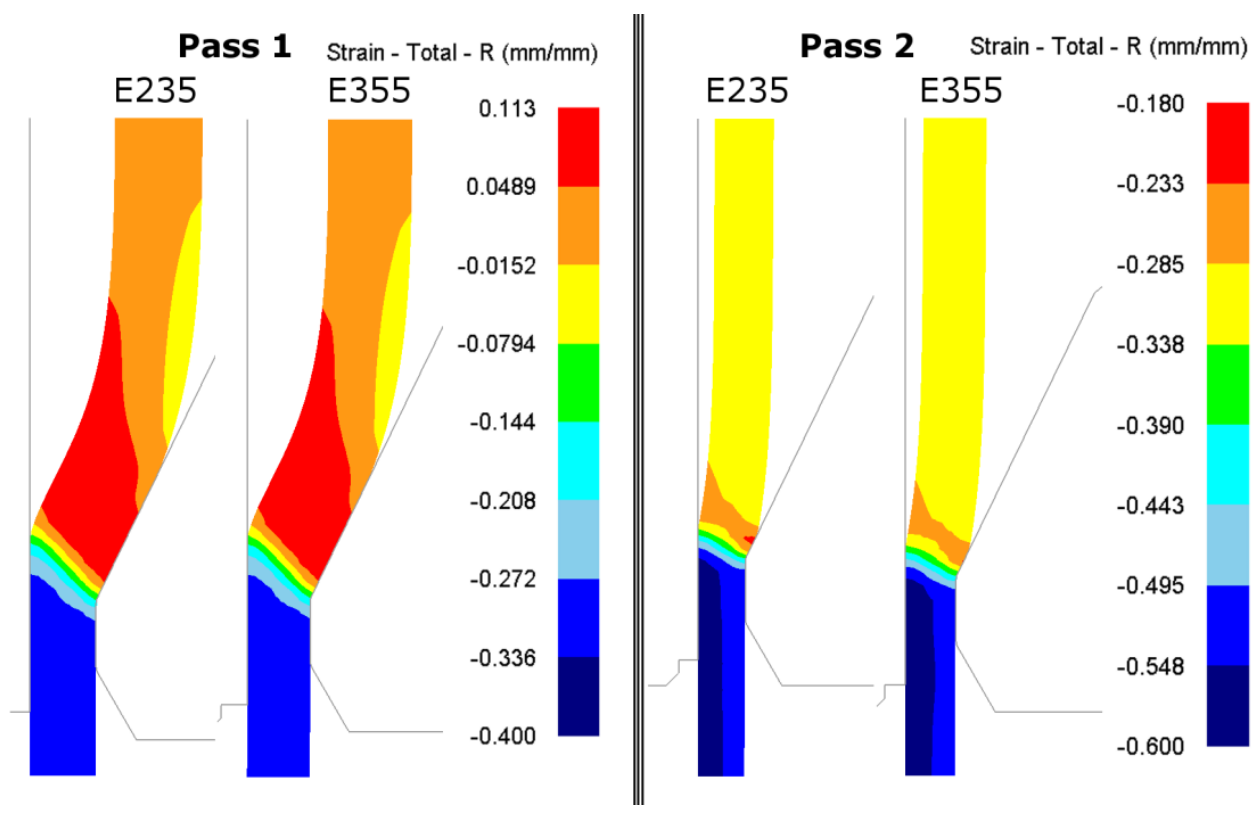

Fig. 4. Pass 1, and pass 2 strain $\varphi 2$ with material E235 and E355.

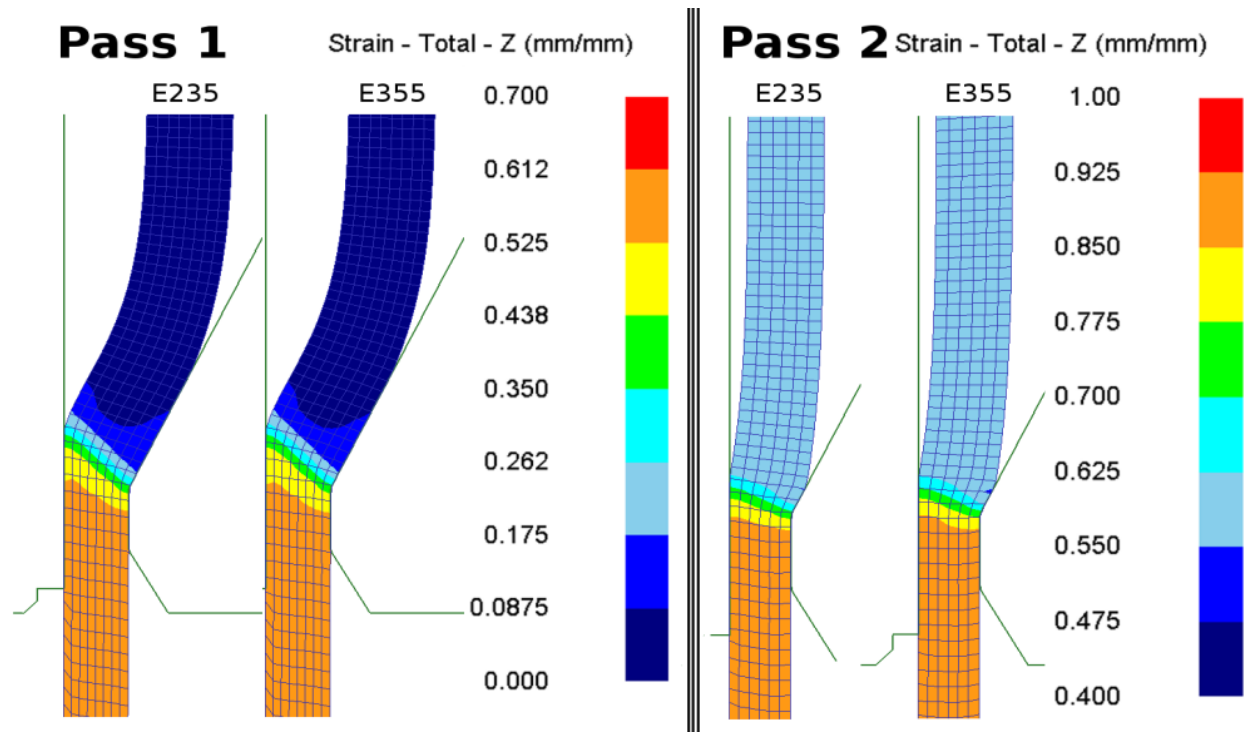

Fig. 5. Pass 1, and pass 2 strain $\varphi 3$ with material E235 and E355.

\section{Conclusion}

The key topic of this paper was to compare S. A. Saltykov, Stereometric metallography method to investigation of deformation with result of numerical FEM simulation using DEFORM 2D software. The result can be summarized in: 
- Beside the experimental investigation using the stereology measurement and FEM simulation are showed very good agreement of final strain values

- By comparing the results of simulation of two different material models (E235 and E355) we can confirm that the material model has a minimal effect on the strain result.

- Simulation using software DEFORM 2D and axisymmetric Lagrangian method can be a valuable tool for prediction deformation strain in cold drawing process.

This work was supported by the Slovak Research and Development Agency under the contract No. APVV-15-0319

\section{References}

1. M. Ridzon̆, Research on technological parameters affecting the production and properties, (PhD thesis) - State Technical University Bratislava, Trnava, (2010)

2. I. Fürbacher, K. Macek, K. Steidl, K. a kol, Lexikon technických materiáli̊ [Lexicon of technical materials], 1, Praha: Verlag Dashöfer, (1999)

3. M. Martinkovic, S. Vaclav, Engineering and Medicine, 5, 585 - 588 (2013)

4. S. A. Saltykov, Stereometric metallography, 3, Metallurgia, Moskva, (1970)

5. T. Holmquist, G. Johnson, J. de Physique IV Colloque, 01 (C3), C3-853-C3-860, (1991)

6. M. Martinkovic, Ceramics-Silikáty, 61.2, 141-146 (2017) 
